\title{
Patrick Noel, FACS, FASMBS, Mediclinic Middle East, Dubai
}

\author{
Marius Nedelcu ${ }^{1,2}$
}

Published online: 20 April 2021

(C) The Author(s), under exclusive licence to Springer Science+Business Media, LLC, part of Springer Nature 2021

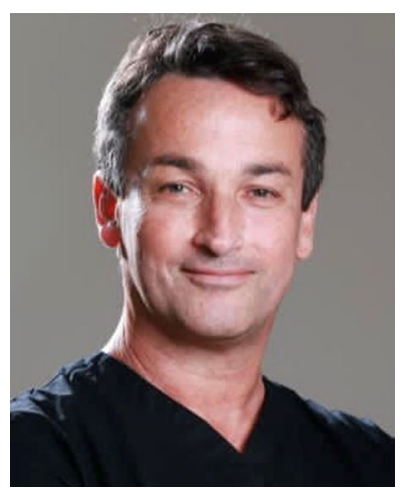

Dr. Patrick Noel was born on May 3, 1962. During his childhood and early adolescence, he grew up in French Guiana discovering the Amazonian Forest and developing his adventurous personality. Dr. Noel graduated from the University of Medicine in Bordeaux and continued his training in surgery in Montpellier in the early 1990s, at the beginning of the laparoscopic approach, under the mentorship of Prof. Domergue. During this period, a life lasting friendship with David Nocca started and was continuously nourished through French and international projects. International Club of Young Laparoscopic Surgeons (ICYLS) was a great opportunity to meet talented surgeons and great human beings such as Mariano Palermo, Rami Lutfi, Camilo Boza, Edu Jacobs, and many others.

After finishing his training in general laparoscopic surgery in the late 1990s, Dr. Noel was involved in humanitarian works in Vietnam along with Dr. Mouret, one of the fathers of laparoscopy who performed the first worldwide laparoscopic cholecystectomy. He stayed several months in Hanoi, Vietnam, with the purpose to train local surgeons for different laparoscopic techniques. This was an important

Marius Nedelcu

nedelcu.marius@gmail.com

1 ELSAN, Clinique Saint Michel, Toulon, France

2 ELSAN, Clinique Bouchard, Marseille, France period in Dr. Noel's life cultivating the most important part of his character: a great human being full of generosity and compassion. The expression of his qualities was enhanced over the next years when he operated more than 1000 patients from French Guiana.

Ironically, despite the constraints of one of the busiest private practices in France (around 2010), he was able to dedicate even more time and resources to research in the clinical bariatric field. Starting at this point, Prof. Michel Gagner played an extremely important role guiding his scientific activity and becoming a mentor at this later stage. Collaborations included numerous papers on finding the appropriate indication for each procedure, especially for the revisional cases (1), on reducing the "invasivity" of laparoscopy with reduced port approach or single devices $(2,3)$ or on decreasing the rate of complications following sleeve gastrectomy in collaboration with his friend, Dr. Thierry Manos (4). This research has resulted in over 50 articles and 7 book chapters. In fact, his entire list of publications perfectly illustrates his surgical career - the evolution of a young surgeon at the beginning of the laparoscopic era into an international leading figure in bariatric surgery.

During the last decade, Dr. Noel has consecutively served as faculty, moderator, and speaker for the IFSO or ASMBS meetings, and he performed more than twelve live procedures. He became an active reviewer for different journals such as Obesity Surgery, SOARD, Obesity Medicine, Surgery, or others and joined the Obesity Surgery Editorial Board in January of 2021. His experience in the bariatric field was repeatedly recognized worldwide during different Sleeve Consensus Summits in New York, London, and Montreal. He was regularly invited to present his experience in revisional surgery from gastric banding to sleeve gastrectomy, resleeve gastrectomy, or the management of different complications following sleeve. All this experience was synthetized by publishing the book The Perfect Sleeve Gastrectomy with Mariano Palermo, David Nocca, Almino Ramos, and Michel Gagner.

The industry and development of new approaches represent a major characteristic of Dr. Noel's activity in metabolic 
and bariatric surgery. Dr. Noel has often taken the initiative of working with industry, or he was included in the development of new products or approaches useful to the field of metabolic/ bariatric surgery. Few projects are worth being discussed. From the early beginning, he was actively involved in the clinical immersion of the new device BariClip with the major purpose to offer an alternative for selected cases to the most common performed bariatric procedure (LSG). Dr. Noel is renowned worldwide for his experience with LSG. With more than 3000 LSGs personally performed, he achieved an important decrease of rate of complications, surgical experience being one of the most important factors. Nonetheless, he was always preoccupied by the reflux disease following sleeve, and the new device BariClip could prove a potential to prevent it along with other major advantages. Analyzing the quality of life of patients with BariClip (5) brought him the opportunity to meet Moises Jacob, and Natan Zundel, a veritable leader.

Dr. Noel has always been actively involved in training surgeons for different bariatric procedures. He started more than 12 years ago in France with different workshops about the management of complications in bariatric surgery or revisional surgery. In 2015, Dr. Patrick Noel left France to practice in the UAE and in the Gulf area, focusing on a holistic approach for the treatment of obesity while continuing to organize workshops to present his experience in bariatric surgery. Recently, he has been invited with the same purpose in Australia. But his willingness for training colleagues is best illustrated by the UpSurg project, a telementoring platform. The idea was to connect the UpSurg platform to any operating room, to allow surgeons to perform live streaming, but especially to improve surgical outcome by experts' opinions in difficult surgical scenarios. With all this proven interest in industry and new techniques, Dr. Patrick Noel has been invited to be an advisor on the board of various investment funds.

As far as this author is concerned, I have had the privilege to meet him and his beautiful family and have got to know them better over the last 2 decades. His beloved wife, Anne, has always been supportive of his projects and surgical activity. They have three children: Romain, project leader for enterprise resource planning in Canada; Pauline, involved in the bariatric field as dietician in Lyon; and Elae involved in modeling in Paris.

\section{References}

1. Noel P, Nedelcu A, Eddbali I, et al. Five-year results after resleeve gastrectomy. Surg Obes Relat Dis. 2020;16(9):1186-91.

2. Nedelcu M, Eddbali I, Noel P. Three-port sleeve gastrectomy: complete posterior approach. Surg Obes Relat Dis. 2016;12(4):925-7.

3. Noel P, Nedelcu M. Gagner M.SPIDER @ sleeve gastrectomy-a new concept in single-trocar bariatric surgery: initial experience and technical details. J Visc Surg. 2014;151(2):91-6.

4. Noel P, Nedelcu M, Gagner M. Impact of the surgical experience on leak rate after laparoscopic sleeve gastrectomy. Obes Surg. 2016;26(8):1782-7.

5. Noel P, Nedelcu AM, Eddbali I, et al. Laparoscopic vertical clip gastroplasty - quality of life. Surg Obes Relat Dis. 2018;14(10): 1587-93.

Publisher's Note Springer Nature remains neutral with regard to jurisdictional claims in published maps and institutional affiliations. 